\title{
Modelling Social Cognitive Theory to Explain Software Piracy Intention
}

\author{
Ameetha Garbharran and Andrew Thatcher \\ School of Human and Community Development, University of the Witwatersrand, \\ Johannesburg, South Africa \\ ameetha@e-pod.co.za, andrew.thatcher@wits.ac.za
}

\begin{abstract}
This study found evidence for a viable social cognitive model of software piracy intention using path analysis. Compared to outcome expectations, moral disengagement emerged as the stronger significant mediator in the model exerting its influence on the relationships between past behaviour and future intention and between past behaviour and outcome expectations. This study found weak evidence for the mediating influence of facilitators and impediments while their impact as a moderating variable was inconclusive.
\end{abstract}

Keywords: social cognitive theory, software piracy, path analysis, social cognitive model, software piracy intention.

\section{Introduction}

Software piracy is a phenomenon whose impact has pervaded the globe. Its appeal, however, has not been confined to the owners of the copyright of digital intellectual property or the groups of individuals that do not believe in the legitimacy of these rights. It has also captured the interest of psychologists who strive to grasp the essence of human behaviour. Recent endeavors yielded theories that sought to deconstruct software piracy intention and behaviour into their basic building blocks. Drawing on insights yielded by some of the more popular social psychological models, this paper proposes a social cognitive model for predicting software piracy intention. In this study software piracy is defined as the unauthorised copying or distribution of digital material [1] without permission from and with no intention to compensate the copyright holders for the use or dissemination of their intellectual property [2].

Social psychology's popular models of human behaviour such as the theory of reasoned action [3], [4], the theory of planned behaviour [5], [6], [7] the theory of interpersonal behaviour [8] and social cognitive theory [9], have examined the constructs that predict intentions to pirate software and software piracy behaviour. The core elements of attitudes, social pressures, intention and behaviour are consistent across the social psychological theories used to investigate software piracy. A significant improvement to the theory of reasoned action (TRA) was a formal acknowledgement of the environment as an influencer of human behaviour which was captured in the controllability dimension of perceived behavioural control in the theory of planned behaviour $(\mathrm{TpB})$, facilitating conditions in the theory of interpersonal 
behaviour (TIB), and facilitators and impediments in social cognitive theory (SCT). While the TIB included affect and habit to understand software piracy intentions and behaviour, social cognitive research in this domain has not emphasised these constructs. As a theoretical paradigm, however, the personal factors construct as a primary determinant of human behaviour in SCT caters for the inclusion of variables such as habit and affective factors. A significant difference between SCT and the other social psychological theories is the incorporation of moral disengagement into its theoretical fabric.

The TpB was found to be superior to the TRA for predicting software piracy intention due to its inclusion of perceived behavioural control [5]. Social cognitive theory was predictively superior to the $\mathrm{TpB}$ in a study investigating intentions to download pirated music. The absence of the self-regulation process in the $\mathrm{TpB}$ (moral disengagement is situated in the self-regulation process in SCT), was one of the reasons it was considered inadequate for explaining the impact of norms on intentions to pirate music [9]. The inclusion of moral disengagement as an intrinsic part of SCT could elevate its predictive utility for explaining antisocial behaviour. Unlike the TpB onto which constructs such as moral obligation and past behaviour were tacked based on the context in which the theoretical framework was applied, moral disengagement, past behaviour, outcome expectations, self-efficacy, and facilitators and impediments are woven into the fabric of SCT as predictors of intention and behaviour. Of the social psychological theories of human behaviour, therefore, SCT is identified as one of the most comprehensive frameworks that explains a wide range of prosocial and antisocial behaviours without having to borrow concepts from other theories.

\section{A Social Cognitive Model of Software Piracy}

Social cognitive theory is a framework for understanding human behaviour in which personal factors, environmental influences and behaviour interact in a pattern of triadic reciprocal causation [10]. Bandura [10] was not explicit about the constituent components of SCT but research on its use in the promotion of healthy behaviours led to the explication of some of its core determinants including, self efficacy, outcome expectations, facilitators and impediments and intention (when behaviour is the outcome variable) [11], [12]. These constructs will be modelled alongside moral disengagement [10] to examine the factors that influence intention to pirate software in this study.

Past behaviour refers to the extent of enactment of a specific behaviour in the past. With behaviour posited as a key determinant of human thought and action, past behaviour is a firm predictor of future behaviour and is inextricably interwoven into SCT. Social cognitive theory defines self efficacy as "people's judgments of their capabilities to organise and execute courses of action required to attain designated types of performances" [10:391]. Moral disengagement refers to the mechanisms individuals activate to override the influence of their internal self-sanctions and to distance themselves from perceived reprehensible consequences of their behaviour [10]. Social cognitive theory is the only framework that caters for the activation of moral disengagement in antisocial contexts. Outcome expectations refer to anticipatory judgments about the likely consequences of actions [10]. Bandura's [10] 
definition of outcome expectations in SCT included attitudes and subjective norms as they have traditionally been defined in the theories of reasoned action and planned behaviour [13]. Facilitators and impediments in SCT encompass situational and contextual factors that render behaviour easier or more difficult to enact [10]. Intention refers to the likelihood of enacting a specific behaviour in the future. In SCT intention is defined as "the determination to perform certain activities or to bring about a certain future state of affairs" [10:467]. Intention is conceptualised as an immediate precursor to behaviour. In studies employing cross-sectional designs (such as this one) it is not feasible to declare behaviour as the dependent variable since all variables are measured concurrently which would imply that any information collected about behaviour would necessarily pertain to past behaviour. In these instances, intention is the logical dependent variable [14].

Empirically, previous enactments of software piracy have had meaningful direct effects on future intention to pirate software [7], [15]. Past behaviour could affect the nature and extent of subsequent moral disengagement. If individuals have pirated software before, it is likely that they will have previously invoked the moral disengagement mechanism. In subsequent enactments, while moral disengagement may still be necessary, it is possible that less moral disengagement is required to distance oneself from the reprehensible consequences of one's actions and/or that the format moral disengagement takes when one is engaging in an antisocial behaviour for the first time compared to when s/he engages in multiple instances of the same antisocial behaviour (or of antisocial behaviour, in general) could vary. Past behaviour could inform subsequent anticipatory judgments about the likely consequences of the same behaviour intended for enactment in the future. If previous enactments led to positive outcomes, it is likely that individuals will form positive outcome expectations about enacting the same behaviour in the future. This conceptualization allows past behaviour to precede moral disengagement and outcome expectations in the model.

There is uncertainty about whether self-efficacy precedes moral disengagement in SCT and some researchers have not accommodated moral disengagement and self-efficacy in the same model when explaining antisocial conduct [16]. In this study self-efficacy is regarded as an exogenous variable which is correlated with past behaviour (if one has successfully pirated software in the past one is likely to have an elevated belief in his/her proficiency to engage in the behaviour in the future). It would have been equally viable to position self-efficacy as an outcome of past behaviour with direct links to outcome expectations and intention and an indirect link to intention through outcome expectations and facilitators and impediments individually and in combination.

The empirical research showed support for direct effects between moral disengagement, outcome expectations and facilitators and impediments on future intention to pirate software [15]. This suggests that if individuals distance themselves from the reprehensible consequences of their actions; if they believe that pirating software will yield positive outcomes; and if they perceive conditions in the environment as enabling, they are more likely to form an intention to pirate software. Evidence for the effect of self-efficacy on intention, however, has been mixed. Garbharran and Thatcher [14] found that the effect of self-efficacy on intention may have been mediated by the facilitators and impediments construct while other research 
yielded a significant direct path between them [15], [17]. If individuals have the proficiency to pirate software it could influence their intentions to engage in the behaviour. However, simply believing in one's ability to enact a behaviour does not imply that one will necessarily execute it. Therefore, it is likely that expectations of positive outcomes envisaged from performing the behaviour could mediate the relationship between self-efficacy and intention. This relationship was investigated in a study by LaRose and Kim [9] who found that outcome expectations acted as a partial mediator of the relationship between self-efficacy and intention. It is also likely that the perception of enabling conditions in the environment could serve as an incentive to individuals who are adept at pirating software to form positive outcome expectations and, consequently, develop future piracy intentions.

The mediating role of moral disengagement has been explored in empirical research. However, there is inconclusive evidence for its effect as a mediator between the social cognitive predictors of self-efficacy, social norms and attitudes and intention [17]. A test for its role as a moderator of the relationships between selfefficacy, attitudes and social pressures on intention revealed no moderating effect [18]. This study hypothesises that moral disengagement and outcome expectations, individually and in combination, mediate the relationship between past behaviour and intention, that moral disengagement mediates the relationship between past behaviour and outcome expectations and that outcome expectations mediate the relationship between moral disengagement and intention. The argument for the mediating influence of moral disengagement on the relationship between past behaviour and outcome expectations is individuals who have engaged in software piracy in the past are first required to distance themselves from the egregious consequences of their prospective actions before being able to form positive anticipatory judgments about the consequences of engaging in the same behaviour in the future. The mediating influences of outcome expectations and moral disengagement individually on the relationship between past behaviour and intention suggest that if individuals have pirated software before, they need to form positive anticipatory judgments about the likely consequences of their choices first before developing future intentions to pirate software; and if individuals have pirated software previously the extent to which they are able to distance themselves from the negative consequences of their intended behaviour is likely to inform their future intentions. The mediating effect of moral disengagement and outcome expectations in combination on the relationship between past behaviour and intention suggests that if individuals have pirated software before, they first need to morally disengage in order to develop positive expectations of the outcomes of their intended behaviour before forming future intentions to pirate.

External environmental effects have directly affected actual piracy behaviour in previous research [8]. In the context of a cross-sectional research design where intention is the dependent variable, environmental influences are hypothesised to have a direct effect on piracy intention. In the model under construction in this study, facilitators and impediments are further believed to mediate the effects of moral disengagement, outcome expectations and self-efficacy on intention. If individuals morally disengage from the negative consequences of a behaviour, anticipate positive outcomes from engaging in the behaviour and/or perceive they have the efficacy to enact the behaviour, factors in the environment which either act as enablers or inhibitors to the formation of software piracy intentions could mediate these relationships. 
This exploratory study is geared towards answering the following research questions:

1. Does the social cognitive model offer a viable explanation of software piracy intention?

2. Do moral disengagement and outcome expectations act as mediators in the model?

3. Do facilitators and impediments mediate or moderate paths in the model?

\section{Method}

Sample. The sample consisted of a group of 456 professionals from a range of industry sectors in South Africa. There was a larger proportion of males $(77 \%)$ than females $(23 \%)$ in the sample. Individuals between the ages of 35 and 54 made up 55\% of the sample while individuals between the ages of 18 and 34 comprised $20 \%$ and the remaining $25 \%$ was made up of individuals aged 55 and above. The largest proportion of individuals in the sample $(48 \%)$ achieved formal university qualifications (undergraduate: 15\%; postgraduate: $33 \%$ ) and worked in the information technology sector $(43 \%)$.

Procedure. Data was collected using an online survey tool. Emails, with a link to the online survey, were sent to prospective respondents from a database of consumers of technology-oriented products and services from a large telecommunications organisation inviting them to complete the survey. Invitations were followed by a reminder email. Data collection spanned two and half months.

Measurements. A questionnaire was developed to measure the social cognitive constructs for explaining software piracy intention. It consisted of 27 items clustered into six discrete scales for past behaviour, moral disengagement, self-efficacy, outcome expectations, facilitators and impediments and intention. Items for selfefficacy, outcome expectations, moral disengagement, facilitators and impediments and intention were measured using a 5-point Likert-type scale which ranged from strongly disagree (1) to strongly agree (5). The 5-point Likert-type rating scale for past behaviour ranged from never (1) to very often (5).

Analysis. The data were analysed using the CALIS procedure in SAS9.2. A path analysis was conducted to test the fit of the model to the data and to derive estimates of the hypothesised paths. Direct and indirect effects were analysed to detect the presence of mediator variables and multiple-group path analysis was performed to test for the presence of a moderator.

\section{Results}

Internal reliabilities were measured using Cronbach's coefficient alpha and are reported in Table 1 together with means and standard deviations. 
Table 1. Reliability estimates, means, standard deviations and intercorrelations

\begin{tabular}{|c|c|c|c|c|c|c|c|c|c|c|c|}
\hline & Variable & Items & $\begin{array}{l}\text { Cronbach's } \\
\alpha\end{array}$ & Mean & SD & 1 & 2 & 3 & 4 & 5 & 6 \\
\hline 1 & Intention & 3 & 0.86 & 6.08 & 2.94 & 1.00 & & & & & \\
\hline 2 & $\begin{array}{l}\text { Facilitators \& } \\
\text { impediments }\end{array}$ & 6 & 0.61 & 16.65 & 3.97 & $0.42 * *$ & 1.00 & & & & \\
\hline 3 & $\begin{array}{l}\text { Outcome } \\
\text { expectations }\end{array}$ & 4 & 0.71 & 2.63 & 0.80 & $0.57 * *$ & $0.50 * *$ & 1.00 & & & \\
\hline 4 & $\begin{array}{l}\text { Moral } \\
\text { disengagement }\end{array}$ & 8 & 0.87 & 20.23 & 7.05 & $0.60 * *$ & $0.51 * *$ & $0.66^{* *}$ & 1.00 & & \\
\hline 5 & Self-efficacy & 3 & 0.86 & 3.38 & 1.02 & $0.19^{* *}$ & $0.18 * *$ & $0.28 * *$ & 0.07 & 1.00 & \\
\hline 6 & Past behaviour & 3 & 0.83 & 1.09 & 1.22 & $0.60 * *$ & $0.32 * *$ & $0.50 * *$ & $0.51 * *$ & $0.21 * *$ & 1.00 \\
\hline
\end{tabular}

The proposed model was evaluated using the maximum likelihood estimation technique and the covariance matrix was analysed. The overall model fit indices suggested a good fit to the data $\left(\chi_{(2, N=456)}^{2}=0.084, p=0.646 ;\right.$ SRMSR $=0.011$; RMSEA $=0.000$ [90\% CI=0.00-0.073], $\mathrm{CFit}=0.858 ; \mathrm{GFI}=0.999 ; \mathrm{CFI}=1.000 ;$ Critical $\mathrm{N}=3118$ ). However, the residuals and modification indices hinted at points of strain. The Wald test suggested that the direct path from self efficacy to intention could be dropped without negatively impacting overall model fit. The chi-square difference test $\left(\chi_{\text {diff }(1, N=456)}^{2}=0.77, p=0.858\right)$ revealed no significant decrement in model fit from eliminating the direct path between self-efficacy and intention. Therefore, this path was dropped to yield the final model tested in this study; depicted in Figure 1.

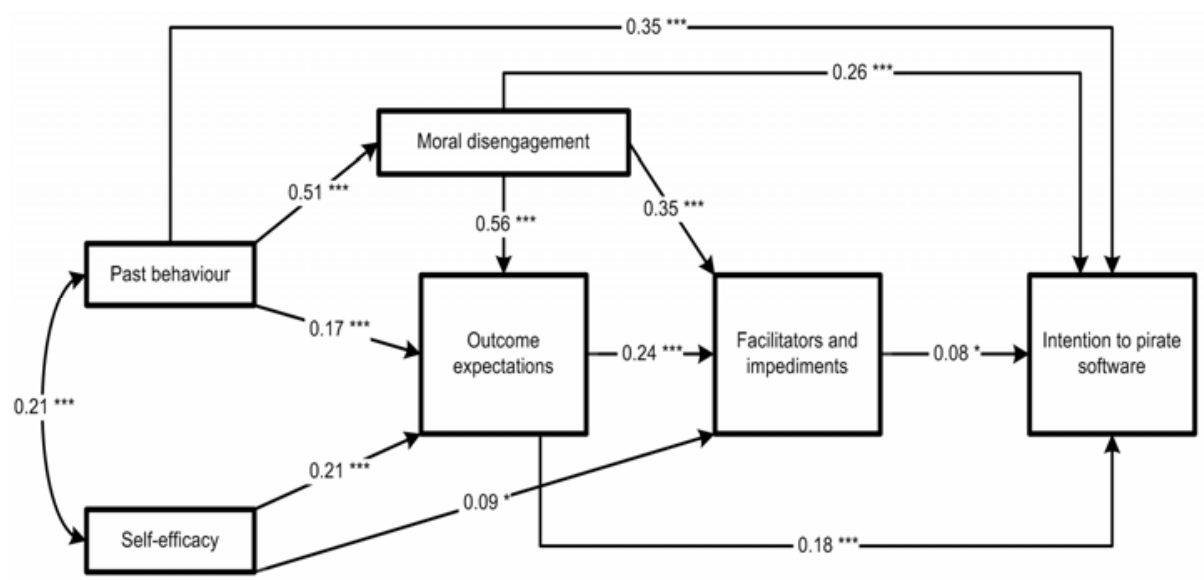

\footnotetext{
* $\mathrm{p}<0.05 \quad * * * \mathrm{p}<0.001$

Model fit summary: $\chi_{(3, N=456)}^{2}=1.640, p=0.650 ;$ SRMSR $=0.011 ;$ RMSEA $=0.000[90 \% \mathrm{CI}=0.00-$ $0.062]$, CFit $=0.898 ; \mathrm{GFI}=0.999 ; \mathrm{CFI}=1.000 ;$ Critical $\mathrm{N}=2168$.
}

Fig. 1. Path coefficients for a social cognitive model of software piracy intention

An evaluation of overall goodness of fit $\left(\chi_{(3, N=456)}^{2}=1.640, p=0.650 ; \mathrm{SRMSR}=0.011\right.$; RMSEA=0.000 [90\% CI=0.00-0.062], CFit=0.898; GFI=0.999; CFI=1.000; Critical 
$\mathrm{N}=2168$ ) of the final model suggested that it fitted the data well. The residuals and modification indices did not indicate localised areas of strain. The path coefficients (depicted in Figure 1) were statistically significant and in the predicted direction [19]. The model explained $51 \%$ of the variance in intention (the main dependent variable).

To test the hypothesis of whether facilitators and impediments acted as a moderator, a multiple-group path analysis was conducted. The sample was split into two groups based on perceptions of high and low facilitating conditions in the environment, to assess changes in the relationships between past behaviour and intention, moral disengagement and intention and outcome expectations and intention at different levels of facilitators and impediments. While the findings presented in Table 2 suggested that the model with facilitators and impediments as a moderator did not offer an adequate fit to the data, preliminary analyses revealed that facilitators and impediments seemed to be a significant moderator of the relationships between past behaviour and intention and moral disengagement and intention. However, it did not appear to moderate the relationship between outcome expectations and intention as hypothesised. Instead a significant moderating effect for facilitators and impediments was found between past behaviour and moral disengagement.

Table 2. Tests for the effect of facilitators and impediments as a moderating variable

\begin{tabular}{|c|c|c|c|c|c|}
\hline & $\chi^{2}$ & $d f$ & $\chi_{\text {diff }}^{2}$ & $d f_{\text {diff }}$ & $p$ \\
\hline Null model: All parameters constrained & 43.99 & 17 & & & \\
\hline Past behaviour $\Rightarrow$ Intention released & 38.17 & 16 & 5.82 & 1 & 0.02 \\
\hline Past behaviour $\Rightarrow$ Moral disengagement released & 39.56 & 16 & 4.44 & 1 & 0.04 \\
\hline Moral disengagement $\Rightarrow$ Intention released & 39.70 & 16 & 4.29 & 1 & 0.04 \\
\hline Outcome expectations $\Rightarrow$ Intention released & 42.43 & 16 & 1.56 & 1 & 0.21 \\
\hline Past behaviour $\Rightarrow$ Intention + & 32.54 & 14 & 11.45 & 3 & $<0.01$ \\
\hline \multirow{2}{*}{\multicolumn{6}{|c|}{ Past behaviour $\Rightarrow$ Moral disengagement +}} \\
\hline & & & & & \\
\hline
\end{tabular}

Note: The sample was split into two groups based on high and low scores on the facilitators and impediments construct to test its effect as a moderating variable.

Overall model fit summary: $\chi_{(14, N=456)}^{2}=32.54, p<0.003$; SRMSR $=0.093$; RMSEA $=0.076[90 \% \mathrm{CI}=$ $0.421-0.111], \mathrm{CFit}=0.095 ; \mathrm{GFI}=0.975 ; \mathrm{CFI}=0.972 ;$ Critical $\mathrm{N}=332$

Model $1\left(\right.$ Low F+I) fit summary: SRMSR $=0.085 ; \mathrm{GFI}=0.987 ; \mathrm{NFI}=0.976 ; 26 \%$ contribution to $\chi^{2}$

Model 2 (High F+I) fit summary: SRMSR $=0.102 ;$ GFI $=0.961 ; \mathrm{NFI}=0.928 ; 74 \%$ contribution to $\chi^{2}$

\section{Discussion}

The social cognitive model investigated in this study is viable and offers one possible explanation of intention to pirate software. The model investigated in this study was one of two believed to offer equally plausible explanations of intention to pirate software. In the equivalent model, self-efficacy was an endogenous variable with a direct relationship to past behaviour. Both models fit the data equally well and the authors leave it to the reader to decide which theoretical interpretation is more meaningful.

A significant indirect effect was noted between past behaviour and outcome expectations (direct $=0.18, \mathrm{p}<0.001$; indirect $=0.29, \mathrm{p}<0.001$ ). In this study it was hypothesised that moral disengagement mediated this relationship and the findings confirmed that this construct was a significant partial mediator of the relationship 
between past behaviour and outcome expectations. This implies that the enactment of software piracy in the past does not presuppose the automatic expectation of positive outcomes for engaging in the same behaviour in the future. Prior software piracy behaviour presupposes that the moral disengagement mechanism was activated previously. This finding suggests that despite its prior activation, further moral disengagement may be necessary in order for individuals who have pirated software in the past to form positive outcome expectations about engaging in the behaviour again in the future.

The relationship between past behaviour and future intention was characterised by a significant indirect effect (direct $=0.35, p<0.001$; indirect $=0.24, p<0.001$ ) suggesting that moral disengagement, outcome expectations and facilitators and impediments acted as partial mediators in the model. These findings imply that in order for individuals who have pirated software in the past to form intentions to pirate software again in the future, it is necessary for them to activate the moral disengagement mechanism, to consider software piracy an act that will lead to beneficial outcomes and to believe that external environmental forces will aid their intended behaviour. The indirect effect of moral disengagement $(0.13, p<0.001)$ and outcome expectations $(0.10, p<0.01)$ on the relationships between past behaviour and intention revealed that moral disengagement was more statistically significant. This suggests that moral disengagement is likely to be a more meaningful mediator of the relationship between past behaviour and future intention.

The effect of self-efficacy on future intention appeared to be completely mediated by the facilitators and impediments construct (direct $=0.03, p<0.38$; indirect $=0.05$, $p<0.001)$ while the indirect effect of outcome expectations on the relationship between self-efficacy and intention was not significant (direct $=0.17, p<0.001$; indirect $=0.02, p<0.07)$. The direct path between self-efficacy and intention was not significant and was consequently dropped from the model. However, its effect through the facilitators and impediments variable was significant but weak. This study did not find a strong or significant direct path between self-efficacy and intention to pirate software suggesting that one's belief in one's efficacy to engage in the behaviour did not automatically translate into software piracy intentions. Instead, the effect of self-efficacy on intention was mediated through facilitators and impediments to influence intentions suggesting that if one had the efficacy to engage in a behaviour, one was more likely to form intentions to enact that behaviour if the environment presented enabling conditions.

Facilitators and impediments appeared to mediate the relationship between selfefficacy and software piracy intention. Its role as a mediator was significant but weak. Traditionally, environmental influences moderate the relationships between variables of theoretical interest. This implies that relationships are likely to be impacted by different levels of facilitators and impediments in the environment. It seems that individuals who pirated software in the past are more likely to develop future intentions to pirate software if there are strong environmental enablers to support their intended actions. It also seems that morally disengaging from negative consequences of the behaviour is more likely to lead to the formation of software piracy intentions in the context of strong environmental enablers. Based on the findings in this study, 
individuals who pirated software in the past were more likely to morally disengage from the reprehensible consequences of their actions when strong environmental facilitators supported the enactment of the intended behaviour. However, it seems counterintuitive that positive outcome expectations led to intentions to pirate software regardless of the level of environmental enablers as it would be expected that the expectation of positive outcomes from pirating software would lead to the formation of software piracy intentions in the context of strong environmental enablers. This unexpected finding could be an artifact of a construct with poor reliability and/or a poor fitting model and requires corroboration.

\section{Limitations and Directions for Future Research}

This study was cross-sectional and could only offer tentative explanations of causality among the social cognitive variables. A longitudinal research design in future research endeavors could better clarify questions of causality and temporal precedence. In addition, a longitudinal design would cater for the inclusion of behaviour as the primary outcome variable. It is possible that facilitators and impediments could moderate the relationship between intention and behaviour such that higher levels of facilitators in the environment will translate into piracy behaviour if intentions to pirate software were formed whereas low levels of enablers in the environment could inhibit software piracy behaviour even if individuals form intentions to engage in the behaviour. This should be explored in future research.

\section{Conclusion}

The social cognitive model offered a viable explanation of intention to pirate software rendering it a useful theoretical framework to explain software piracy; one instance of antisocial behaviour. Moral disengagement, SCT's unique contribution to explaining antisocial behaviour, was identified as the strongest mediator between past behaviour and outcome expectations in the model highlighting the necessity for further moral disengagement in individuals who had previously engaged in software piracy in order to form positive outcome expectations about the possibility of engaging in the behaviour in the future. This suggested that moral disengagement may not be a onceoff process even when the envisaged future behaviour is identical in principle to past behaviour. Thus, while the nature and/or extent of moral disengagement may alter over time, it does not become redundant in the context of multiple enactments of the same behaviour. Moral disengagement was a more significant mediator than outcome expectations of the relationship between past behaviour and future piracy intention. Weak yet significant evidence for the mediating effect of facilitators and impediments in the proposed model was found. Even though this study was unable to comment conclusively on the moderating role of facilitators and impediments in a social cognitive model of software piracy intention, preliminary findings suggested that facilitators and impediments may be more optimal as moderators of the relationships between social cognitive constructs. 
Acknowledgments. We thank Michael Greyling from the Department of Psychology at the University of the Witwatersrand for his expert statistical input. The financial assistance of the National Research Foundation (NRF) towards this research is hereby acknowledged. Opinions expressed and conclusions arrived at are those of the authors and may not necessarily be attributed to the NRF.

\section{References}

1. Business Software Alliance, http: / / www.bsa.org/country.aspx?sc_lang=en-ZA

2. Gopal, R.D., Sanders, G.L.: International software piracy: Analysis of key issues and impacts. Info. Sys. Research 9(4), 380-397 (1998)

3. Eining, M.M., Christensen, A.L.: A psycho-social model of software piracy: the development and test of a model. In: Dejoie, R., Fowler, G., Paradice, D. (eds.) Ethical Issues in information systems, pp. 182-188. Boyd \& Fraser, Boston (1991)

4. Woolley, D.J., Eining, M.M.: Software piracy among accounting students: A longitudinal comparison of changes and sensitivity. J. Info. Sys. 20(1), 49-63 (2006)

5. Chang, M.K.: Predicting unethical behavior: A comparison of the theory of reasoned action and the theory of planned behavior. J. Bus. Eth. 17, 1825-1834 (1998)

6. Peace, A.G., Galletta, D.F., Thong, J.Y.L.: Software piracy in the workplace: A model and empirical test. J. Mngt. Info. Sys. 20(1), 153-177 (2003)

7. Cronan, T.P., Al-Rafee, S.: Factors that influence the intention to pirate software and media. J. Bus. Eth. 78, 527-545 (2008)

8. Limayem, M., Khalifa, M., Chin, W.W.: Factors motivating software piracy: a longitudinal study. IEEE Trans. Eng. Mngt. 51, 414-425 (2004)

9. LaRose, R., Kim, J.: Share, steal or buy? A social cognitive perspective of music downloading. CyberPsych. \& Beh. 10(2), 267-277 (2007)

10. Bandura, A.: Social foundations of thought and action: A social cognitive theory. PrenticeHall, Englewood Cliffs (1986)

11. Bandura, A.: Self-efficacy: The exercise of control. W.H. Freeman and Company, New York (1997)

12. Bandura, A.: Health promotion by social cognitive means. Health Educ. \& Beh. 31(2), 143-164 (2004)

13. Ajzen, I.: The theory of planned behavior. Org. Beh. \& Hum. Proc. 50, 179-211 (1991)

14. Garbharran, A., Thatcher, A.: A case for using a social cognitive model to explain intention to pirate software. J. eHealth Tech. \& App. 7(2), 87-98 (2009)

15. Garbharran, A., Thatcher, A. (under review): Predicting software piracy intentions in organisations: Does organisation size matter? J. Bus. Eth. (2010)

16. Bandura, A., Barbaranelli, C., Caprara, G.V., Pastorelli, C.: Mechanisms of moral disengagement in the exercise of moral agency. J. Pers. \& Soc. Psych. 71, 364-374 (1996)

17. Matthews, M.S.: Bandura's social cognitive theory in a cross-nation study of software piracy. Unpublished masters research report. University of the Witwatersrand, Johannesburg, South Africa (2009)

18. Wentzell, A.: The implementation of social cognitive theory in the understanding of the unauthorised copying of software. Unpublished masters research report. University of the Witwatersrand, Johannesburg, South Africa (2008)

19. Brown, T.A.: Confirmatory Factor Analysis for Applied Research. The Guilford Press, New York (2006) 